\title{
Pain in Canadian Veterans: Analysis of data from the Survey on Transition to Civilian Life
}

\author{
Elizabeth G VanDenKerkhof $\mathrm{DrPH}^{1}$, Linda VanTil ${ }^{2}$, James M Thompson MD CCFP(EM) FCFP ${ }^{2,3}$, Jill Sweet $\mathrm{MSc}^{2}$, \\ Wilma M Hopman $\mathrm{MA}^{3,4}$, Meg E Carley BSc ${ }^{5}$, Kerry Sudom $\mathrm{PhD}^{6}$
}

\author{
EG VanDenKerkhof, L VanTil, JM Thompson, et al. Pain in \\ Canadian Veterans: Analysis of data from the Survey on Transition \\ to Civilian Life. Pain Res Manag 2015;20(2):89-95.
}

BACKGROUND: Little is known about the prevalence of chronic pain among Veterans outside the United States.

OBJECTIVE: To describe the prevalence of chronic pain and associated sociodemographic, health behaviour, employment/income, disability, and physical and mental health factors in Canadian Veterans.

METHODS: The 2010 Survey on Transition to Civilian Life included a nationally representative sample of 3154 Canadian Armed Forces Regular Force Veterans released from service between 1998 and 2007. Data from a telephone survey of Veterans were linked with Department of National Defence and Veterans Affairs Canada administrative databases. Pain was defined as constant/reoccurring pain (chronic pain) and as moderate/ severe pain interference with activities.

RESULTS: Forty-one percent of the population experienced constant chronic pain and $23 \%$ experienced intermittent chronic pain. Twenty-five percent reported pain interference. Needing help with tasks of daily living, back problems, arthritis, gastrointestinal conditions and age $\geq 30$ years were independently associated with chronic pain. Needing help with tasks of daily living, back problems, arthritis, mental health conditions, age $\geq 30$ years, gastrointestinal conditions, low social support and noncommissioned member rank were associated with pain interference.

CONCLUSIONS: These findings provide evidence for agencies and those supporting the well-being of Veterans, and inform longitudinal studies to better understand the determinants and life course effects of chronic pain in military Veterans.

Key Words: Associated factors; Chronic pain; Military; Prevalence; Veterans

\section{La douleur chez les anciens combattants canadiens : une analyse des données tirées de l'Enquête sur la transition à la vie civile}

\begin{abstract}
HISTORIQUE : On ne sait pas grand-chose de la prévalence de la douleur chronique chez les anciens combattants qui ne vivent pas aux États-Unis. OBJECTIF : Décrire la prévalence de la douleur chronique et des facteurs associés aux variables sociodémographiques, aux comportements liés à la santé, à l'emploi et au revenu, aux invalidités et à la santé physique et mentale chez les anciens combattants canadiens.

MÉTHODOLOGIE : L'Enquête sur la transition à la vie civile de 2010 incluait un échantillon national représentatif de 3154 anciens membres de la force régulière des Forces armées canadiennes libérés du service militaire entre 1998 et 2007. Les chercheurs ont relié les données obtenues lors d'une enquête téléphonique auprès des anciens combattants aux bases de données administratives du ministère de la Défense nationale et des Anciens Combattants Canada. La douleur était définie comme une douleur persistante ou récurrente (douleur chronique) et comme une douleur modérée à grave qui nuisait aux activités.

RÉSULTATS : Quarante et un pour cent des membres de l'échantillon ressentaient des douleurs chroniques persistantes et $23 \%$, des douleurs chroniques intermittentes. Vingt-cinq pour cent ont déclaré des interférences causées par la douleur. Le besoin d'aide pour les activités de la vie quotidienne, les problèmes de dos, l'arthrite, les affections gastro-intestinales et un âge de 30 ans ou plus s'associaient de manière indépendante à la douleur chronique. Le besoin d'aide pour les activités de la vie quotidienne, les problèmes de dos, l'arthrite, les problèmes de santé mentale, un âge de 30 ans ou plus, les affections gastro-intestinales, un manque de soutien social et le grade de militaire du rang s'associaient aux interférences causées par la douleur.

CONCLUSIONS : Ces observations fournissent des preuves aux organismes et aux dispensateurs qui appuient le mieux-être des anciens combattants et orientent les études longitudinales afin de mieux comprendre les déterminants de la douleur chronique et leurs effets sur la vie des anciens combattants.
\end{abstract}

Few studies have examined characteristics associated with chronic pain in Veterans. In a prospective study involving Veterans of OEF/OIF, women were significantly more likely than men to report back and musculoskeletal pain one and seven years after discharge from service $(n=450,329)(8)$. In a cross-sectional study in the United States, women exhibited a lower prevalence of pain compared with men, but higher prevalence of moderate to severe pain $(n=91,414)(7)$. In the same study, being married, lower levels of education, being enlisted and being in the army were associated with chronic pain (7). In a cross-sectional study involving United States Veterans Affairs Veterans in a primary care setting, being younger, reporting worsening health over the past year, emotional distress, smoking, diet issues, weight concerns and use of more outpatient health care services were associated with chronic pain (10).

Current evidence suggests a high prevalence of chronic pain in Veterans; however, there are no studies involving Canadian Veterans. prevalence ranged from $43 \%$ to $48 \%(6-9)$.

${ }^{1}$ School of Nursing and Deptartment of Anesthesiology 8 Perioperative Medicine, Queen's University, Kingston, Ontario; ${ }^{2}$ Veterans Affairs

Canada, Charlottetown, Prince Edward Island; ${ }^{3}$ Department of Public Health Sciences, Queen's University; ${ }^{4}$ Clinical Research Centre,

Kingston General Hospital; ${ }^{5}$ School of Nursing, Queen's University, Kingston; ${ }^{6}$ Department of National Defence, Ottawa, Ontario

Correspondence: Dr Elizabeth VanDenKerkhof, School of Nursing, 92 Barrie Street, Queen's University, Kingston, Ontario K7L 3 N6.

Telephone 613-533-6000 ext 74743,fax613-533-6770, e-mail ev5@queensu.ca

OPEN $\bigcirc$ ACCESS

This open-access article is distributed under the terms of the Creative Commons Attribution Non-Commercial License (CC BY-NC) (http:// creativecommons.org/licenses/by-nc/4.0/), which permits reuse, distribution and reproduction of the article, provided that the original work is properly cited and the reuse is restricted to noncommercial purposes. For commercial reuse, contact support@pulsus.com 


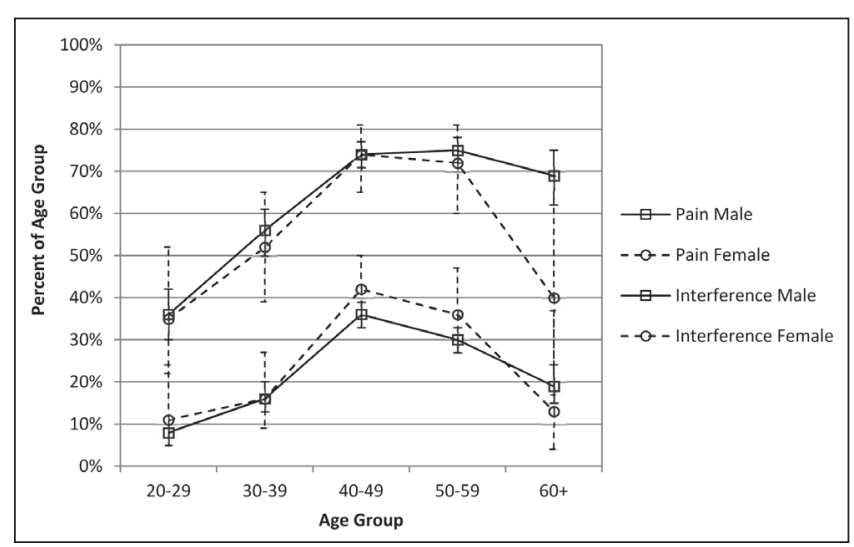

Figure 1) Prevalence of chronic pain in Canadian military Veterans according to age and sex

The prevalence of chronic pain and associated characteristics may differ between Veterans in Canada versus the United States due to military service factors, such as role in conflict zones, and conditions after release from the military, such as access to health and social services. Recent Canadian studies suggest that chronic pain in Veterans is associated with low physical health-related quality of life (11) and suicidal ideation (12). The purpose of the present study was to explore the prevalence of chronic pain in Canadian Veterans and identify potential correlates of chronic pain. This will enable comparison with international studies involving Veterans. The objectives were: to describe the prevalence of constant or reoccurring chronic pain/discomfort (chronic pain) and pain-related interference with activities (pain interference); and to identify sociodemographic, health behaviour, employment/income, disability, and physical and mental health factors associated with chronic pain and pain interference.

\section{METHODS}

Data for the present analysis came from the Survey on Transition to Civilian Life, a cross-sectional study of Canadian Armed Forces (CAF) Regular Force Veterans who were released from service between January 1, 1998 and December 31, 2007. Only 30.4\% of Veterans in the target population are Veterans Affairs Canada (VAC) clients. Therefore, a stratified random sample was drawn that included an oversampling of VAC clients (14). Veterans living in institutions, the Territories or outside Canada, serving outside Canada, or still serving in the military were excluded. Of the 4721 Veterans sampled, the response rate was $71 \%$. Ninety-four percent agreed to share responses with VAC and the Department of National Defense (DND), providing a nationally representative sample of 3154 . Sixty-six percent were not clients of VAC. The current analysis is based on the sample of 3154 Veterans, which represents a weighted total population of 32,015. Military characteristics, VAC status and demographic characteristics were obtained through data linkage with DND and VAC administrative databases and self-report. Details of this computerassisted telephone survey conducted by Statistics Canada and the variables contained and extracted from the DND and VAC administrative databases are reported elsewhere (13).

The objectives of the Survey on Transition to Civilian Life were to capture self-reported information on health, disability and determinants of health of former CAF members (14). The questionnaire sought information on multiple factors, limiting the ability to collect detailed data on pain. The questionnaire included three questions about pain: "Do you have any pain or discomfort that is always present? (yes/no)"; "Do you have any pain or discomfort that reoccurs from time to time? (yes/ no)"; and "During the past four weeks, how much did pain interfere with your normal work (including work both outside the home and housework)? (not at all/a little bit/moderately/quite a bit/extremely)". The first two questions are similar to questions from the Health Utility Index, and the third question comes from the Short Form-12 Health
Outcomes Survey (2,15-17). For the purpose of the present study, pain was defined in two ways: constant or reoccurring pain or discomfort (responded 'yes' for questions 1 and 2; which were referred to as chronic pain) and moderate to severe pain that interfered with activities (selected 'moderately', 'quite a bit' or 'extremely' for question 3; which was referred to as pain interference).

Several factors known to be associated with chronic pain in the general population $(1,2,17-20)$ were examined in the present analysis, including age, sex, education, marital status, household income and employment status. Health-related characteristics included tobacco and alcohol use, diagnosed chronic physical health conditions, body mass index (BMI) and diagnosed mental health conditions. Activity limitation was measured as needing help with at least one basic or instrumental activity of daily living. In addition, military characteristics, including years of service and rank, were examined. Continuous variables were categorized as follows: 10-year age intervals, household income quartiles, years of service $(<2,2$ to 9,10 to $19, \geq 20)$ and BMI $\left(<25 \mathrm{~kg} / \mathrm{m}^{2}=\right.$ underweight $/$ normal, $\geq 25 \mathrm{~kg} / \mathrm{m}^{2}$ to $<30 \mathrm{~kg} / \mathrm{m}^{2}=$ overweight and $\geq 30 \mathrm{~kg} / \mathrm{m}^{2}=$ obese).

All physical and health-related data were captured through selfreport. Details about questions and responses are reported elsewhere (13). Missing data were minimal with the exception of alcohol consumption (13\% missing) and income (5.0\%). An 'undisclosed' category was created for these variables to allow for the inclusion of the missing respondents.

Statistics Canada respondent sampling weights were applied to account for VAC client status, age, sex and nonresponse $(21,22)$. Data analysis included frequencies and percentages for all independent variables and the two outcome variables. Mean and SD was also calculated for age. Independent variables were cross-tabulated with pain outcome variables. The cross-tabulations were conducted on the sample to ensure adequate sample size to conduct a robust analysis before applying sampling weights. The $\chi^{2}$ test was used to assess for differences in the distribution of demographic and clinical variables for those who have chronic pain and those who do not. The same analyses were conducted for those who have moderate to severe pain interference and those who do not. Statistically significant variables identified in the bivariate analyses were included in the multivariable logistic regression analyses. Backwards manual stepwise methods were used to eliminate variables until the most parsimonious model remained. At each iteration, the variable contributing the least to the model was removed. Only variables with $\mathrm{P}<0.05$ were retained in the final models. Results are expressed as OR and 95\% CIs. All analyses were conducted using Stata 11.1 (www.stata.com); $\mathrm{P}<0.05$ was considered to be statistically significant. Ethics approval was obtained from the Queen's University Research Ethics Board (Kingston, Ontario).

\section{RESULTS}

The mean $( \pm$ SD) age of Veterans was $44 \pm 10$ years (range 20 to 67 years), $88 \%$ were men and $60 \%$ were married. Forty-seven percent had high school education or less. Fifty-three percent were in the military for $\geq 20$ years, $58 \%$ were junior or senior noncommissioned officers, $21 \%$ were senior officers and $21 \%$ were private/recruits. Twenty-four percent of the population reported at least one mental health condition. The highest prevalence was reported for anxiety or depression $(20 \%)$, followed by anxiety or mood disorder $(12 \%)$ and post-traumatic stress disorder (11\%).

Forty-one percent of Veterans experienced constant pain or discomfort, and $23 \%$ experienced reoccurrent pain. The weight-adjusted combined prevalence of constant/reoccurring pain (chronic pain) was $64 \%$. The prevalence of chronic pain ranged from $36 \%$ (20 to 29 years of age) to $75 \%$ ( 50 to 59 years of age) among men and 35\% (20 to 29 years of age) to $74 \%$ (40 to 49 years of age) among women. The prevalence of moderate to severe pain interference in the total population of Veterans was $25 \%$. Pain interference ranged from $8 \%$ (20 to 29 years of age) to $36 \%$ (40 to 49 years of age) among men and $11 \%$ (20 to 29 years of age) to $42 \%$ (40 to 49 years of age) among women (Figure 1). 
TABLE 1

Sociodemographic characteristics of the study population

\begin{tabular}{|c|c|c|c|c|c|c|c|}
\hline \multirow[b]{2}{*}{ Characteristic* } & \multirow[b]{2}{*}{$\%$ of total sample } & \multicolumn{3}{|c|}{ Pain, always or recurrent } & \multicolumn{3}{|c|}{ Pain interference with work, moderate to extreme } \\
\hline & & Sample, $\mathbf{n}$ & $\begin{array}{l}\text { Weighted, total } \\
\text { population, } n\end{array}$ & $\begin{array}{l}\text { Weighted, } \\
\% \text { with pain }\end{array}$ & Sample, $\mathbf{n}$ & $\begin{array}{l}\text { Weighted, total } \\
\text { population, } \mathrm{n}\end{array}$ & $\begin{array}{c}\text { Weighted, } \\
\% \text { with pain }\end{array}$ \\
\hline \multicolumn{8}{|l|}{ Sex } \\
\hline Female & 12 & 373 & 3785 & 63 & 371 & 3775 & 30 \\
\hline \multicolumn{8}{|l|}{ Age group, years } \\
\hline $20-29$ & 16 & 304 & 5047 & 36 & 304 & 5046 & 8.2 \\
\hline $40-49$ & 34 & 1251 & 10798 & 74 & 1249 & 10,782 & 37 \\
\hline $50-59$ & 24 & 894 & 7726 & 75 & 893 & 7722 & 31 \\
\hline $60-69$ & 7.9 & 264 & 2534 & 67 & 264 & 2534 & 19 \\
\hline \multicolumn{8}{|l|}{ Education } \\
\hline Less than high school & 6.8 & 233 & 2160 & 68 & 233 & 2160 & 32 \\
\hline High school & 41 & 1345 & 12,991 & 64 & 1342 & 12,972 & 28 \\
\hline 3rd quartile & 27 & 864 & 8736 & 68 & 862 & 8725 & 25 \\
\hline 4th quartile & 19 & 598 & 6959 & 57 & 599 & 6963 & 15 \\
\hline Undisclosed & 5.0 & 156 & 1606 & 63 & 155 & 1602 & 26 \\
\hline \multicolumn{8}{|l|}{ Employment status } \\
\hline Employed & 75 & 2188 & 24,112 & 61 & 2188 & 24,108 & 20 \\
\hline Not employed & 25 & 959 & 7852 & 74 & 955 & 7833 & 42 \\
\hline \multicolumn{8}{|l|}{ Smoker type } \\
\hline Daily & 19 & 617 & 6085 & 68 & 616 & 6082 & 33 \\
\hline Occasional & 5.3 & 163 & 1706 & 63 & 163 & 1706 & 26 \\
\hline Nonsmoker & 76 & 2367 & 24,166 & 64 & 2364 & 24,148 & 24 \\
\hline \multicolumn{8}{|l|}{ Drinker type } \\
\hline$\geq 20$ & 53 & 1916 & 16,877 & 73 & 1912 & 16,855 & 30 \\
\hline \multicolumn{8}{|l|}{ Military rank } \\
\hline Officer & 21 & 553 & 6551 & 52 & 553 & 6551 & 11 \\
\hline Senior NCM & 28 & 1043 & 9025 & 75 & 1042 & 9018 & 33 \\
\hline Junior NCM & 31 & 1127 & 9634 & 79 & 1124 & 9619 & 38 \\
\hline Private/Recruit & 21 & 427 & 6778 & 41 & 427 & 6777 & 12 \\
\hline
\end{tabular}

${ }^{*}$ All comparisons were significant at $P<0.05$. NCM Noncommissioned member

The distribution of sociodemographic characteristics according to the presence of chronic pain and moderate to severe pain interference are provided in Table $1 . \chi^{2}$ testing indicated that the distribution of all demographic characteristics differed between those with chronic pain and those who did not report chronic pain $(\mathrm{P}<0.05)$. Chronic pain was most common in Veterans with the following characteristics: 10 to 19 years of military service, rank of junior noncommissioned officer, 50 to 59 years of age, unemployed, undisclosed alcohol consumption, less than high school education, daily smoker and male sex. Similar findings were present for pain interference, except women were more likely than men to report pain interference.

Chronic pain and pain interference were highly prevalent in Veterans with physical conditions such as arthritis, gastrointestinal issues, back problems and respiratory issues (Table 2). Pain was also highly prevalent in the presence of mental health conditions.
Eighty-five percent of Veterans with at least one mental health condition had chronic pain and $55 \%$ had pain interference. The prevalence of chronic pain was high in Veterans with depression or anxiety $(86 \%)$, anxiety or mood disorder $(88 \%)$, and post-traumatic stress disorder (93\%). In addition, $95 \%$ of individuals with mental health conditions also had at least one physical health condition. The prevalence of chronic pain was highest in the subgroup of Veterans who were obese, compared with overweight and normal/underweight Veterans.

Table 3 reports the findings of the most parsimonious model for chronic pain. The strongest association was found for requiring help with activities, followed by back problems and arthritis. Given that back problems and arthritis may be highly correlated with requiring help, the model was rerun after requiring help with activities was removed. The odds of chronic pain increased for back problems (OR 10.89 [95\% CI 8.26 to 14.35$]$ ), arthritis (OR 9.23 [95\% CI 6.24 to 
TABLE 2

Health characteristics of the study population

\begin{tabular}{|c|c|c|c|c|c|c|c|}
\hline \multirow[b]{2}{*}{ Characteristic* } & \multirow[b]{2}{*}{$\%$ of total sample } & \multicolumn{3}{|c|}{ Pain, always or recurrent } & \multicolumn{3}{|c|}{ Pain interference with work ${ }^{\dagger}$} \\
\hline & & Sample, $n$ & $\begin{array}{c}\text { Weighted, total } \\
\text { population, } n\end{array}$ & Weighted, \% & Sample, $n$ & $\begin{array}{c}\text { Weighted, total } \\
\text { population, } n\end{array}$ & Weighted, \% \\
\hline \multicolumn{8}{|l|}{ Needs help with activities } \\
\hline Never & 44 & 943 & 13,974 & 32 & 943 & 13,973 & 1.8 \\
\hline \multicolumn{8}{|l|}{ Back problems } \\
\hline Yes & 40 & 1546 & 12,813 & 92 & 1544 & 12,802 & 45 \\
\hline \multicolumn{8}{|l|}{ Arthritis } \\
\hline Yes & 23 & 992 & 7459 & 95 & 991 & 7456 & 55 \\
\hline No & 77 & 2145 & 24,413 & 55 & 2141 & 24,390 & 16 \\
\hline \multicolumn{8}{|l|}{ Diabetes } \\
\hline Yes & 5.5 & 214 & 1760 & 77 & 214 & 1760 & 37 \\
\hline No & 95 & 2931 & 30,199 & 64 & 2926 & 30,173 & 25 \\
\hline Yes & 18 & 685 & 5872 & 77 & 685 & 5871 & 34 \\
\hline No & 82 & 2456 & 26,045 & 61 & 2451 & 26,019 & 23 \\
\hline \multicolumn{8}{|l|}{ Gastrointestinal disorder } \\
\hline Yes & 11 & 448 & 3514 & 91 & 448 & 3514 & 54 \\
\hline No & 89 & 2681 & 28,315 & 61 & 2676 & 28,289 & 22 \\
\hline \multicolumn{8}{|l|}{ Respiratory disorder } \\
\hline Yes & 8.0 & 278 & 2408 & 80 & 278 & 2408 & 41 \\
\hline No & 92 & 2691 & 27,524 & 63 & 2687 & 27,502 & 24 \\
\hline \multicolumn{8}{|l|}{ Body mass index } \\
\hline Normal/underweight & 29 & 777 & 9058 & 56 & 775 & 9050 & 19 \\
\hline Overweight & 43 & 1361 & 13,551 & 64 & 1360 & 13,543 & 25 \\
\hline
\end{tabular}

${ }^{*}$ All analysis are significant at $P<0.05{ }^{\dagger}{ }^{+}$Moderate to extreme interference with work

13.66]) and age (30 to 39 years, OR 1.79 [95\% CI 1.24 to 2.58]; 40 to 49 years, OR 3.07 [95\% CI 2.20 to 4.28]; 50 to 59 years, OR 3.17 [95\% CI 2.23 to 4.52 ]; $\geq 60$ years, OR 1.65 [95\% CI 1.04 to 2.63]).

Table 4 reports the findings for the pain interference model. Similar to the chronic pain model, requiring help with activities had the highest odds of pain interference. Removal of this variable from the model changed the ORs for some of the other variables but not to the same extent as in the chronic pain model; back problems (OR 3.33 [95\% CI 2.68 to 4.13$]$ ), arthritis (OR 3.77 [95\% CI 3.02 to 4.72]), having a mental health condition (OR 2.73 [95\% CI 2.16 to 3.44]), older age (40 to 49 years OR 3.00 [95\% CI 1.77 to 5.11 ]; 50 to 59 years OR 2.23 [95\% CI 1.29 to 3.88]), having gastrointestinal problems (OR 1.79 [95\% CI 1.30 to 2.46]), low social support (OR 1.48 [95\% CI 1.19 to 1.83]), being unemployed (OR 2.3 [95\% CI 1.85 to 2.9]) and being a junior noncommissioned member remained nonsignificant (OR 1.02 [95\% CI 0.65 to 1.59]); however, the OR increased to being the same as the OR for private/recruit (reference category).

\section{DISCUSSION}

The present study was the first to explore the epidemiology of chronic pain in Canadian Veterans and, in addition to a Finnish study, one of the only studies outside of the United States. Sixty-four percent of Canadian Veterans experienced constant or intermittent chronic pain or discomfort, and $25 \%$ had moderate to severe interference with activities due to pain. After controlling for several significant covariates, there was a strong association between physical health conditions and the presence of chronic pain and moderate to severe pain interference. Mental health conditions were associated with pain interference but not with the presence of chronic pain.

The prevalence of $64 \%$ with constant or reoccurring chronic pain in our study is higher than the range reported in a recent systematic review of chronic pain in Veterans (25\% to 50\%) (5); however, our finding of $41 \%$ with constant pain is consistent with the review. The definition of chronic pain in our study is closest to the measure used in a convenience sample of Veterans from primary care in the VA Connecticut Healthcare System (10), which obtained a prevalence of $48 \%$ (10). Our estimate is higher than international estimates of approximately 30\% (23) and Canadian estimates that range from $18 \%$ to $35 \%(2,17,24,25)$. The Canadian National Population Health Survey definition (18\%) is based on constant pain only (ie, "are you usually free of pain or discomfort?"), while our definition is based on constant or reoccurring pain or discomfort. The heterogeneity in prevalence estimates in Veteran and civilian populations is partially due to the variability in sampling techniques, populations studied and measurement tools used. Research involving chronic pain is more advanced in the general populations, in whom more studies have been conducted using more detailed and validated measurement tools. This has likely led to the more refined range of estimates in general populations $(2,17,23,26)$.

Some physical health conditions were up to twice as prevalent in this Veteran population than in the age- and sex-adjusted Canadian general population: back problems, arthritis, gastrointestinal conditions 
TABLE 3

Factors associated with chronic pain in Canadian Veterans

\begin{tabular}{|c|c|c|c|c|}
\hline $\begin{array}{l}\text { Independent } \\
\text { variables* }\end{array}$ & Unadjusted OR & $95 \% \mathrm{Cl}$ & Adjusted OR & $95 \% \mathrm{Cl}$ \\
\hline \multicolumn{5}{|c|}{ Needs help with activities of daily living } \\
\hline No & 1.0 & & 1.0 & \\
\hline Yes & 18.96 & $15.20-23.64$ & 8.36 & $6.54-10.68$ \\
\hline \multicolumn{5}{|c|}{ Back problems } \\
\hline No & 1.0 & & 1.0 & \\
\hline Yes & 13.86 & $10.67-18.00$ & 7.15 & $5.27-9.71$ \\
\hline \multicolumn{5}{|l|}{ Arthritis } \\
\hline No & 1.0 & & 1.0 & \\
\hline Yes & 14.43 & $10.04-20.74$ & 5.49 & $3.59-8.40$ \\
\hline \multicolumn{5}{|c|}{ Gastrointestinal conditions } \\
\hline No & 1.0 & & 1.0 & \\
\hline Yes & 6.93 & $4.43-10.83$ & 2.64 & $1.54-4.51$ \\
\hline \multicolumn{5}{|l|}{ Age, years } \\
\hline $20-29$ & 1.0 & & 1.0 & \\
\hline $30-39$ & 2.24 & $1.63-3.10$ & 1.55 & $1.05-2.31$ \\
\hline $40-49$ & 5.23 & $3.93-6.96$ & 1.97 & $1.39-2.81$ \\
\hline $50-59$ & 5.37 & $3.98-7.24$ & 1.80 & $1.23-2.65$ \\
\hline$\geq 60$ & 3.75 & $2.58-5.45$ & 1.20 & $0.71-2.03$ \\
\hline
\end{tabular}

${ }^{*}$ Removed from model in the following order: diabetes, mental health condition, smoking, respiratory condition, hypertension, length of service, alcohol, education, rank, obesity, heart disease, sex, employment, income, social support

and obesity (13). Back problems, arthritis and gastrointestinal conditions were associated with chronic pain and pain interference. Musculoskeletal disorders and gastrointestinal disorders are commonly associated with chronic pain and discomfort in other populations (27-32). These findings are supported by the association between physical health-related quality of life and chronic pain reported in a previous study involving this study population (11).

Seventy-one percent of Veterans were overweight or obese, which is slightly higher than the estimate of $60 \%$ in the general population $(13,33)$. The prevalence of chronic pain and pain interference was higher for overweight and obese Veterans; however, after adjusting for other factors, BMI was not retained in the final multivariate model. Obesity has been correlated with chronic pain in other studies $(20,34,35)$ and the relationship is believed to be multifactorial (36). The finding of a strong association between chronic pain and physical health conditions, such as musculoskeletal disorders, suggests that painful health conditions for which obesity is a risk factor could have mediated the effect of obesity, which would account for the lack of association between obesity and chronic pain and pain interference in the final models. Furthermore, musculoskeletal disorders may contribute to activity limitation, which may lead to obesity, and vice versa $(20,37-40)$.

Other physical health problems, such as heart disease and diabetes, were not associated with chronic pain or pain interference in the adjusted model in our study. Physical health conditions accumulate with age; however, some conditions may be more prevalent at earlier ages. For example, arthritis and back problems are more common earlier in life than heart disease or adult-onset diabetes. This was a relatively young population with a mean age of 44 years; thus, larger sample sizes are likely required to detect associations between heart disease or diabetes and chronic pain.

In bivariate analysis, $85 \%$ of Veterans with at least one mental health condition had chronic pain and $55 \%$ had pain interference compared with $58 \%$ and $16 \%$, respectively, of Veterans without a mental health condition. Additionally, $95 \%$ of respondents with a mental health condition also had a physical health condition. In multivariable regression, mental health conditions were not associated with chronic pain independently of chronic musculoskeletal and gastrointestinal
TABLE 4

Factors associated with pain interference with activities (moderate to severe) in Canadian Veterans

\begin{tabular}{|c|c|c|c|c|}
\hline $\begin{array}{l}\text { Independent } \\
\text { variables* }\end{array}$ & Unadjusted OR & $95 \% \mathrm{Cl}$ & Adjusted OR & $95 \% \mathrm{Cl}$ \\
\hline \multicolumn{5}{|c|}{ Needs help with activities } \\
\hline No & 1.0 & & 1.00 & \\
\hline Yes & 41.88 & $26.22-66.89$ & 17.45 & $10.23-29.73$ \\
\hline \multicolumn{5}{|l|}{ Back problems } \\
\hline No & 1.0 & & 1.00 & \\
\hline Yes & 5.84 & $4.89-6.98$ & 2.22 & $1.77-2.79$ \\
\hline \multicolumn{5}{|l|}{ Arthritis } \\
\hline No & 1.0 & & 1.00 & \\
\hline Yes & 6.27 & $5.24-7.50$ & 2.77 & $2.21-3.47$ \\
\hline \multicolumn{5}{|c|}{ Mental health condition } \\
\hline No & 1.0 & & 1.00 & \\
\hline Yes & 6.13 & $5.12-7.34$ & 2.08 & $1.64-2.65$ \\
\hline \multicolumn{5}{|l|}{ Age, years } \\
\hline 20-29 & 1.0 & & 1.00 & \\
\hline $30-39$ & 2.10 & $1.32-3.33$ & 1.07 & $0.58-1.96$ \\
\hline $40-49$ & 6.50 & $4.30-9.82$ & 2.06 & $1.12-3.80$ \\
\hline $50-59$ & 4.89 & $3.21-7.45$ & 1.41 & $0.75-2.66$ \\
\hline$\geq 60$ & 2.53 & $1.54-4.14$ & 0.82 & $0.40-1.71$ \\
\hline \multicolumn{5}{|c|}{ Gastrointestinal problems } \\
\hline No & 1.0 & & 1.00 & \\
\hline Yes & 4.11 & $3.26-5.18$ & 1.56 & $1.16-2.15$ \\
\hline \multicolumn{5}{|c|}{ Low social support } \\
\hline No & 1.0 & & 1.00 & \\
\hline Yes & 2.56 & $2.16-3.03$ & 1.30 & $1.04-1.63$ \\
\hline \multicolumn{5}{|l|}{ Employed } \\
\hline No & 1.0 & & 1.00 & \\
\hline Yes & 0.34 & $0.29-0.41$ & 0.43 & $0.34-0.54$ \\
\hline \multicolumn{5}{|l|}{ Rank } \\
\hline Private/recruit & 1.0 & & 1.00 & \\
\hline Officer & 0.88 & $0.61-1.27$ & 0.32 & $0.18-0.58$ \\
\hline Senior NCM & 3.42 & $2.52-4.65$ & 0.62 & $0.36-1.08$ \\
\hline Junior NCM & 4.34 & $3.20-5.89$ & 0.71 & $0.43-1.20$ \\
\hline
\end{tabular}

${ }^{*}$ Removed from model in the following order: sex, diabetes, heart disease, length of service, education, respiratory condition, obesity, alcohol, income, hypertension, smoking. NCM Noncommissioned member

conditions. Respondents may have understood the phrase "pain or discomfort" to relate more to physical than mental health conditions. However, chronic pain is well known to have mental health dimensions (41), which could, in part, explain why physical and mental health conditions were independently associated with interference with activity by pain. The importance of the co-occurrence of physical and mental health conditions in the epidemiology of disability is well established in population studies (42-48), and the findings of our study implicate the role of painful physical health conditions together with mental health status in disability in Veterans.

In the present study, being employed and having higher levels of income decreased the odds of pain interference, which is supported by the literature $(2,20,25)$. Military rank reflects socioeconomic factors and was also associated with pain interference. In bivariate analysis, noncommissioned member rank was associated with increased odds of pain interference before controlling for physical and mental health conditions. Noncommissioned members had the highest rates of medical release, physical and mental health conditions and activity limitations in this population (48). It is possible that the disproportionate rate of chronic health conditions in former noncommissioned members, especially painful musculoskeletal conditions, are attributable to higher occupational physical demands. 
Studies in the United States have reported similar gradients in selfreported health according to rank and higher odds of disability discharge in Veterans with physically demanding occupations (49-52).

The prevalence of chronic pain and pain interference was highest in Veterans 40 to 59 years of age and prevalence decreased for those $\geq 60$ years of age. Reports describing the relationship between chronic pain and age are inconsistent; however, the results in the current study support the findings in a large European study of chronic pain in the general population in which prevalence declined in the older age groups, particularly after 60 years of age (1). In a systematic review investigating pain in Veterans, only one study identified age as a correlate of chronic pain and higher rates were also reported in younger Veterans compared with older Veterans (5). Specific age categories were not provided. The finding of lower levels of pain in older age groups may be related to expectations that pain is normal with aging and, therefore, individuals may be less likely to report it. Another factor may be that pain interference decreases, because work-related activity usually decreases with age. The socioemotional selectivity theory may also contribute to decreased pain reports with older age. This theory posits that as time horizons shrink (ie, as people age), individuals increasingly focus on positive thoughts or memories (53).

The prevalence of chronic pain was similar for women $(63 \%)$ and men $(65 \%)$, while women were more likely to report moderate to severe pain interference ( $30 \%$ of women versus $25 \%$ of men). These findings are similar to a study involving OEF/OIF Veterans in the United States in which women had a lower prevalence of chronic pain compared with men, even after adjusting for other factors, but they were slightly more likely to report moderate to severe pain (7). The lack of a statistically significant association for sex in the final models may be related to a lack of statistical power owing to the low proportion of women compared with men in the study, or factors that moderate the relationship between sex and pain. However, the low numbers of women in the survey limited the analysis. Future prospective studies in larger cohorts of women Veterans are needed to explore these outcomes further.

A strength of the present study was the ability to generalize findings to all Regular Force Veterans who transitioned to civilian life from the Canadian military between 1998 and 2007. Random sampling and weighting of the sample to the total population to account for VAC status, age, sex and nonresponse also contribute to the generalizability of the findings (13). The good response rate and high consent-to-share rate reduced the likelihood of response bias. Sociodemographic and military characteristics were captured from DND administrative databases rather than self-report, thereby minimizing recall bias.

A limitation of the present study was that indicators and determinants of health were captured by self-report. There is potential for under- or

\section{REFERENCES}

1. Breivik H, Collett B, Ventafridda V, Cohen R, Gallacher D. Survey of chronic pain in Europe: Prevalence, impact on daily life, and treatment. Eur J Pain 2006;10:287-333.

2. Reitsma ML, Tranmer JE, Buchanan DM, Vandenkerkhof EG. The prevalence of chronic pain and pain-related interference in the Canadian population from 1994 to 2008. Chronic Dis Inj Can 2011;31:157-64

3. Reid KJ, Harker J, Bala MM et al. Epidemiology of chronic non-cancer pain in Europe: Narrative review of prevalence, pain treatments and pain impact. Curr Med Res Opin 2011;27:449-62.

4. Institute of Medicine of the National Academies. Relieving Pain in America: A Blueprint for Transforming Prevention, Care, Education, and Research (Report Brief). 2011.

5. Vandenkerkhof EG, Carley ME, Hopman WM, Ross-White A, Harrison MB. Prevalence of chronic pain and related risk factors in military veterans: A systematic review. JBI Database of Systematic Reviews \& Implementation Reports 2014;12:152-86.

6. Gironda RJ, Clark ME, Massengale JP, Walker RL. Pain among veterans of Operations Enduring Freedom and Iraqi Freedom. Pain Med 2006;7:339-43

7. Haskell SG, Brandt CA, Krebs EE, Skanderson M, Kerns RD, Goulet JL. Pain among veterans of Operations Enduring Freedom and Iraqi Freedom: Do women and men differ? Pain Med 2009;10:1167-73. over-reporting health conditions when relying on self-report. However, self-report has long been used in Canadian population health studies to study determinants of health. Self-report is also the standard means of capturing pain outcomes given that pain is a subjective experience. The three questions used to capture pain outcomes are general, do not capture the level of detail available from other validated survey instruments and do not include a measure of pain duration. However, the questions are similar to those used to measure chronic pain in several Canadian studies $(2,15$ 17), allowing for comparison of pain in Canadian Veterans to Canadians in the general population. The study sample was limited to regular forces members; therefore, these findings cannot be generalized to reservists. The findings do not necessarily apply to CAF personnel who deployed to Afghanistan because it was conducted before the conclusion of Canada's Afghanistan combat mission, and most of those who deployed were and even today remain in service and, therefore, were not included in the 2010 survey. The findings cannot be generalized to elderly Veterans, given that the oldest participant in the study sample was 67 years of age. A further limitation is the small sample of women included in the study, which limited the ability to adequately assess the relationship between pain and sex. Due to the cross-sectional nature of the study, causality and directionality of the relationship cannot be determined.

The present study identified a group of Veterans who have a high prevalence of chronic pain and discomfort and pain-related activity interference, along with associated chronic health conditions and socioeconomic barriers. These findings add to the growing knowledge about chronic pain in Veterans, and offer useful information for providers and agencies supporting Veterans' well-being. The results support the importance of considering physical health conditions when treating Veterans with mental health conditions and chronic pain because $95 \%$ of those with mental health conditions had chronic physical health conditions and many chronic physical health conditions are painful. In addition, chronic pain, mental health conditions and physical health conditions are all highly correlated with disability in this population (48). The results of the present study will inform the design of longitudinal studies of chronic pain and research to identify optimum approaches to mitigate chronic pain and the disabling effects of chronic pain in military Veterans.

DISCLOSURES: This study was partially supported by funding from Government of Canada Veterans Affairs \& Department of National Defence, facilitated through the Canadian Institute of Military and Veteran's Health Research. The authors declare that they have no conflicts of interest. Drs Linda VanTil, James M Thompson, Jill Sweet and Kerry Sudom are employed by the Government of Canada.

8. Haskell SG, Ning Y, Krebs E et al. Prevalence of painful musculoskeletal conditions in female and male veterans in 7 years after return from deployment in Operation Enduring Freedom/ Operation Iraqi Freedom. Clin J Pain 2012;28:163-7.

9. Seal KH, Shi Y, Cohen G, et al. Association of mental health disorders with prescription opioids and high-risk opioid use in US veterans of Iraq and Afghanistan. JAMA 2012;307:940-7.

10. Kerns RD, Otis J, Rosenberg R, Reid MC. Veterans' reports of pain and associations with ratings of health, health-risk behaviors, affective distress, and use of the healthcare system. J Rehabil Res Dev 2003;40:371-9.

11. Thompson J, Hopman W, Sweet J, et al. Health-related quality of life of Canadian Forces veterans after transition to civilian life. Can J Public Health 2013;104:e15-e21.

12. Thompson JM, Zamorski M, Sweet J, et al. Role of physical and mental health in suicidal ideation in Canadian Armed Forces Regular Force Veterans. Can J Pub Health 2014; In press.

13. Thompson JM, MacLean MB, Van Til L, et al. Survey on Transition to Civilian Life: Report on Regular Force Veterans. Charlottetown, PE: Veterans Affairs Canada, 2011. < http://publications.gc.ca/ collections/collection_2011/acc-vac/V32-231-2011-eng.pdf> (Accessed February 13, 2014)

14. MacLean MB, Van Til L, Thompson JM, et al. Life After Service Study: Data Collection Methodology for the Income Study and the 
Transition to Civilian Life Survey. Veterans Affairs Canada Research Directorate Technical Report. 2010:79.

15. Millar WJ. Chronic pain. Health Rep 1996;7:47-8.

16. Rashiq S, Dick BD. Factors associated with chronic noncancer pain in the Canadian population. Pain Res Manag 2009;14:454-60.

17. Vandenkerkhof EG, Hopman WM, Towheed TE, Anastassiades TP, Goldstein DH; Canadian Multicentre Osteoporosis Study Research Group. The impact of sampling and measurement on the prevalence of self-reported pain in Canada. Pain Res Manag 2003;8:157-63.

18. Bongers PM, Kremer AM, ter Laak J. Are psychosocial factors, risk factors for symptoms and signs of the shoulder, elbow, or hand/ wrist?: A review of the epidemiological literature. Am J Ind Med 2002;41:315-42.

19. Reitsma M, Tranmer JE, Buchanan DM, Vandenkerkhof EG. The epidemiology of chronic pain in Canadian men and women between 1994 and 2007: Longitudinal results of the National Population Health Survey. Pain Res Manag 2012;17:166-72.

20. Vandenkerkhof EG, Macdonald HM, Jones GT, Power C, Macfarlane GJ. Diet, lifestyle and chronic widespread pain: Results from the 1958 British Birth Cohort Study. Pain Res Manag 2011;16:87-92

21. Statistics Canada. Survey methods and practices. Ottawa: Statistics Canada. Catalogue no. 12-587-X. 2010a;408 p.; 2010. <www. statcan.gc.ca/pub/12-587-x/12-587-x2003001-eng.pdf > (Accessed March 25, 2014)

22. Statistics Canada. Survey on Transition to Civilian Life 2010a Microdata User Guide. Ottawa: Statistics Canada, Special Surveys Division; 2010.

23. Elzahaf RA, Tashani OA, Unsworth BA, Johnson MI. The prevalence of chronic pain with an analysis of countries with a Human Development Index less than 0.9: A systematic review without meta-analysis. Curr Med Res Opin 2012;28:1221-9.

24. Moulin DE, Clark AJ, Speechley M, Morley-Forster PK. Chronic pain in Canada - prevalence, treatment, impact and the role of opioid analgesia. Pain Res Manag 2002;7:179-84.

25. Tripp DA, Vandenkerkhof EG, McAlister M. Prevalence and determinants of pain and pain-related disability in urban and rural settings in southeastern Ontario. Pain Res Manag 2006;11:225-33.

26. Smith BH, Elliott AM, Chambers WA, Smith WC, Hannaford PC, Penny K. The impact of chronic pain in the community. Fam Pract 2001;18:292-9.

27. Badley EM, Rasooly I, Webster GK. Relative importance of musculoskeletal disorders as a cause of chronic health problems, disability, and health care utilization: Findings from the 1990 Ontario Health Survey. J Rheumatol 1994;21:505-14.

28. Woolf AD, Pfleger B. Burden of major musculoskeletal conditions. Bull World Health Organ 2003;81:646-56.

29. Ladabaum U, Boyd E, Zhao WK et al. Diagnosis, comorbidities, and management of irritable bowel syndrome in patients in a large health maintenance organization. Clin Gastroenterol Hepatol 2012;10:37-45.

30. Morrison G, Van Langenberg DR, Gibson SJ, Gibson PR. Chronic pain in inflammatory bowel disease: Characteristics and associations of a hospital-based cohort. Inflamm Bowel Dis 2013;19:1210-7.

31. Tachawiwat K, Cheewadhanaraks S. Prevalence of irritable bowel syndrome among patients with mild-moderate and severe chronic pelvic pain. J Med Assoc Thai 2012;95:1257-60.

32. Reed BD, Harlow SD, Sen A, Edwards RM, Chen D, Haefner HK. Relationship between vulvodynia and chronic comorbid pain conditions. Obstet Gynecol 2012;120:145-51.

33. Canadian Institute for Health Information and the Public Health Agency of Canada. Obesity in Canada: A joint report from the
Public Health Agency of Canada and the Canadian Institute for Health Information. Her Majesty the Queen in Right of Canada. 2011. <https://secure.cihi.ca/free_products/Obesity_in_ canada_2011_en.pdf> (Accessed March 13, 2014).

34. Hitt HC, McMillen RC, Thornton-Neaves T, Koch K, Cosby AG. Comorbidity of obesity and pain in a general population: Results from the Southern Pain Prevalence Study. J Pain 2007;8:430-6.

35. Somers TJ, Wren AA, Keefe FJ. Understanding chronic pain in older adults: Abdominal fat is where it is at. Pain 2011;152:8-9.

36. McVinnie DS. Obesity and pain. Br J Pain 2013;7:163-70.

37. Macfarlane GJ, McBeth J, Silman AJ. Widespread body pain and mortality: Prospective population based study. BMJ 2001;323:662-5.

38. Macfarlane GJ, Jones GT, Knekt P, et al. Is the report of widespread body pain associated with long-term increased mortality? Data from the Mini-Finland Health Survey. Rheumatology (Oxford) 2007;46:805-7.

39. McBeth J, Silman AJ, Macfarlane GJ. Association of widespread body pain with an increased risk of cancer and reduced cancer survival: A prospective, population-based study. Arthritis Rheum 2003;48:1686-92.

40. McBeth J, Symmons DP, Silman AJ et al. Musculoskeletal pain is associated with a long-term increased risk of cancer and cardiovascular-related mortality. Rheumatology (Oxford) 2009;48:74-7.

41. El-Gabalawy R, Asmumdson GJG, Sareen J. Suicide and chronic pain. In: Berman AL, Pompili M, eds. Medical Conditions Associated with Suicide Risk. American Association of Suicidology; 2011:75-86.

42. Bruffaerts R, Vilagut G, Demyttenaere K, et al. Role of common mental and physical disorders in partial disability around the world. Br J Psychiatry 2012;200:454-61.

43. Dewa CS, Lin E, Kooehoorn M, Goldner E. Association of chronic work stress, psychiatric disorders, and chronic physical conditions with disability among workers. Psychiatr Serv 2007;58:652-8.

44. Scott KM, Von KM, Alonso J et al. Mental-physical co-morbidity and its relationship with disability: Results from the World Mental Health Surveys. Psychol Med 2009;39:33-43.

45. Bair MJ, Robinson RL, Katon W, Kroenke K. Depression and pain comorbidity: A literature review. Arch Intern Med 2003;163:2433-45.

46. Banks SM, Kerns RD. Explaining high rates of depression in chronic pain: A diathesis-stress framework. Psychol Bull 1996;119:95-110.

47. Otis JD, Keane TM, Kerns RD. An examination of the relationship between chronic pain and post-traumatic stress disorder. J Rehabil Res Dev 2003;40:397-405.

48. Thompson JM, Pranger T, Sweet J et al. Disability correlates in Canadian Armed Forces Regular Force Veterans. Disabil Rehabil 2014;1-8.

49. Feuerstein M, Berkowitz SM, Peck CA, Jr. Musculoskeletal-related disability in US Army personnel: Prevalence, gender, and military occupational specialties. J Occup Environ Med 1997;39:68-78.

50. Gubata ME, Piccirillo AL, Packnett ER, Cowan DN. Military occupation and deployment: Descriptive epidemiology of active duty U.S. Army men evaluated for a disability discharge. Mil Med 2013;178:708-14.

51. Lincoln AE, Smith GS, Amoroso PJ, Bell NS. The natural history and risk factors of musculoskeletal conditions resulting in disability among US Army personnel. Work 2002;18:99-113.

52. Maclean A, Edwards RD. The pervasive role of rank in the health of U.S. Veterans. Armed Forces Soc 2010;36:765-85.

53. Carstensen LL, Isaacowitz DM, Charles ST. Taking time seriously. A theory of socioemotional selectivity. Am Psychol 1999;54:165-81. 


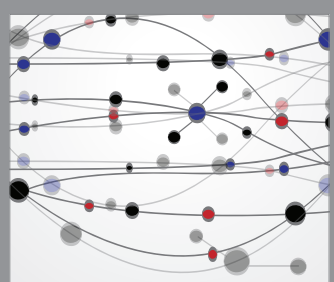

The Scientific World Journal
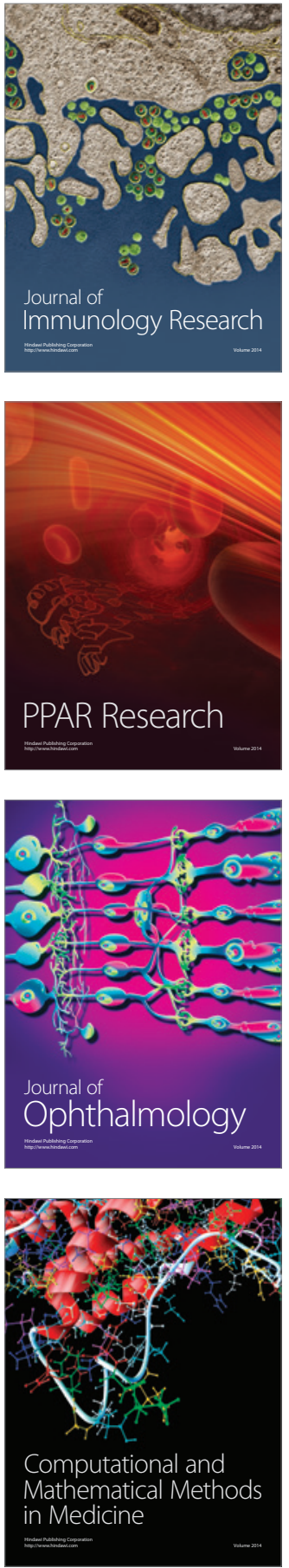

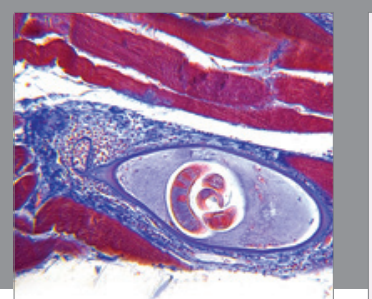

Gastroenterology Research and Practice

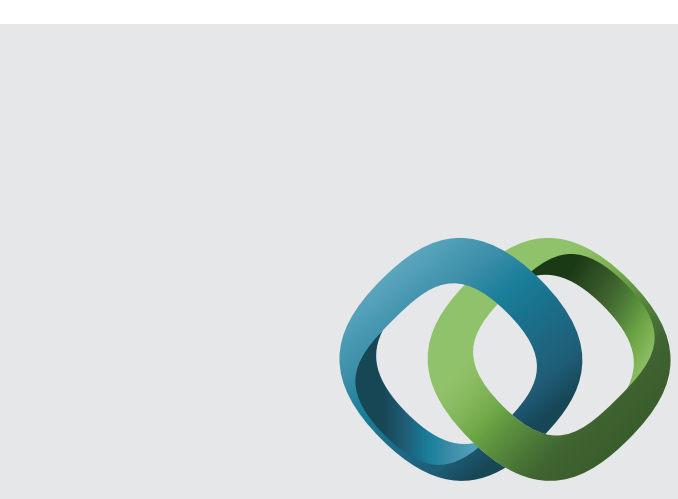

\section{Hindawi}

Submit your manuscripts at

http://www.hindawi.com
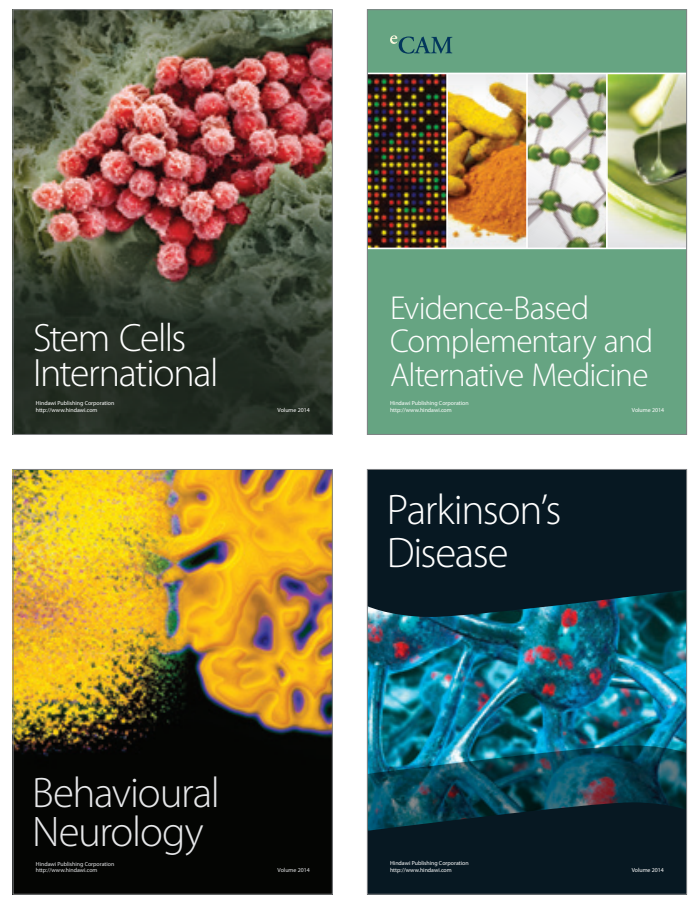
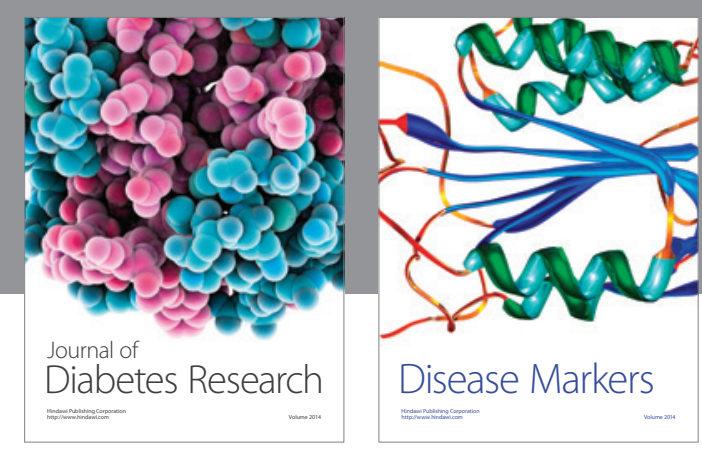

Disease Markers
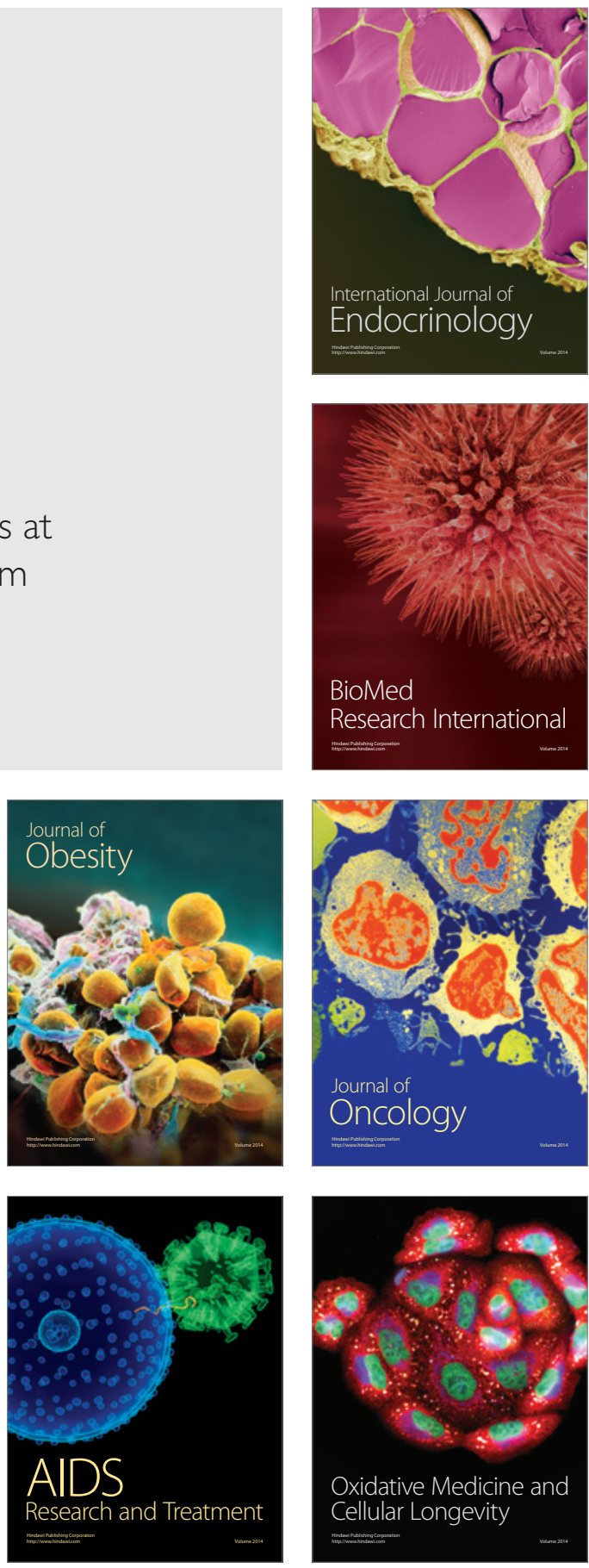